\title{
An Intracardiac Foreign Body: A Missing Suture in an Operated Infant with Congenital Heart Disease
}

\author{
Jennifer Shortland ${ }^{1 *}$, Demetris Taliotis ${ }^{2}$, Andrew Parry ${ }^{3}$ \\ ${ }^{1}$ Department of Paediatric Cardiology, Bristol Royal Hospital for Children, Bristol. United Kingdom. \\ ${ }^{2}$ Department of Paediatric Cardiology, Bristol Royal Hospital for Children, Bristol. United Kingdom. \\ ${ }^{3}$ Department of Paediatric Cardiothoracic Surgery, Bristol Royal Hospital for children, Bristol. United Kingdom. \\ *Corresponding Author: Jennifer Shortland, Department of Paediatric Cardiology, Bristol Royal Hospital for Children, Bristol, BS2 8BJ.
} United Kingdom.

Received: January 05, 2021; Accepted: January 25, 2021; Published: February 05, 2021

Citation: Jennifer Shortland, Demetris Taliotis, Andrew Parry, (2021) An Intracardiac Foreign Body: A Missing Suture in an Operated Infant with Congenital Heart Disease. J Thoracic Disease and Cardiothoracic Surgery, 2(1); Doi:10.31579/2693-2156/014

Copyright: ( 2021 Jennifer Shortland, This is an open-access article distributed under the terms of the Creative Commons Attribution License, which permits unrestricted use, distribution, and reproduction in any medium, provided the original author and source are credited.

\begin{abstract}
Intra-cardiac foreign bodies are a rare occurrence and there is minimal literature on retention of sutures following cardiac surgery.

This is an unusual case of a retained intracardiac prolene suture following surgical correction of Tetralogy of Fallot in a 6 month old patient. The patient had an uneventful post-surgical recovery but a foreign body was identified on a routine post-operative transthoracic echocardiogram. Due to the uncertain nature of the structure, the patient underwent fluoroscopy, chest X-ray and a cardiac CT which were unable to identify the nature of the structure. The best modality for identification was echocardiography, which consistently demonstrated the origin, and course of the suture.

Due to a high level of suspicion and consistent findings on echocardiograms, the patient underwent surgical exploration 10 days following surgery and a prolene suture was identified originating in the right upper pulmonary vein extending though the mitral and aortic valve to the transverse aortic arch. This was thought to be from the purse string suture used for the left ventricular vent inserted via the right upper pulmonary vein during surgery.
\end{abstract}

Keywords: foreign body; congenital heart disease; surgical complication; retained suture

\section{Introduction}

Intra-cardiac foreign bodies are a rare occurrence and there is minimal literature on retained sutures post cardiac surgery. Due to the nonradiopaque structure of the sutures they are difficult to identify on plain radiography [4].

Intra-cardiac foreign bodies without a history of penetrating trauma are rare and may cause serious complications. Foreign bodies can reach the heart in different ways including intra-operatively but the most commonly via migration of a medical device such as inferior cava filters and catheters [1]

Techniques for removing post traumatic or iatrogenic foreign bodies include percutaneous, endovascular and an open surgical approach. The need for removal of foreign bodies should be individualised depending on the nature of the structure, and the actual or potential side effects. Symptomatic foreign bodies causing cardiac tamponade, arrhythmia, fever or anxiety should be removed, asymptomatic foreign bodies identified immediately after the injury in the presence of risk factors such as embolism, arrhythmia or infection should be removed [2] Asymptomatic foreign bodies or those identified late after an injury could be treated conservatively [3].

\section{Case Report}

A 6 month old infant with a background of VACTERL association and long gap oesophageal atresia with upper pouch tracheoesophageal fistula was admitted for routine surgical repair of her Tetralogy of Fallot.

The patient had oesophageal atresia which was repaired at 2 months of age and continued to be followed up by the surgical team as she was felt to be at high risk of stricture.

At 6 months of age the patient was accepted for routine full repair of Tetralogy of Fallot. The surgical repair was performed via median sternotomy. The pericardium was opened and the heart cannulated for cardiopulmonary bypass. A vent was placed via the right upper pulmonary vein across the mitral valve into the left ventricle and secured in place with a $5 / 0$ prolene suture. The right ventricular outflow tract obstruction was relieved with division and excision of muscle bundles, 
and the native valve was spared. The ventricular septal defect was closed with a pericardial patch and the right atrium was closed. Even though it is our unit's standard practice to perform a transoesophageal echocardiogram for all bypass cases, it was felt to be contraindicated in this case due to the previous history of long segment oesophageal atresia and an epicardial echocardiogram was performed instead. This demonstrated a satisfactory repair and the patient came of bypass without difficulty.

Following surgery the patient returned to PICU where she made a good recovery and was discharged to the cardiology ward within 24 hours following a transthoracic echocardiogram which demonstrated a good surgical repair with mild residual pulmonary stenosis and only a small VSD patch leak.

The patient remained clinically stable and was planned for home discharge at day 7. However, detailed transthoracic echocardiograms demonstrated a linear, thin and brightly echogenic structure originating from the right upper pulmonary vein and passing across the mitral and aortic valve and terminating in the thoracic aorta (Figure 1a-1d.)

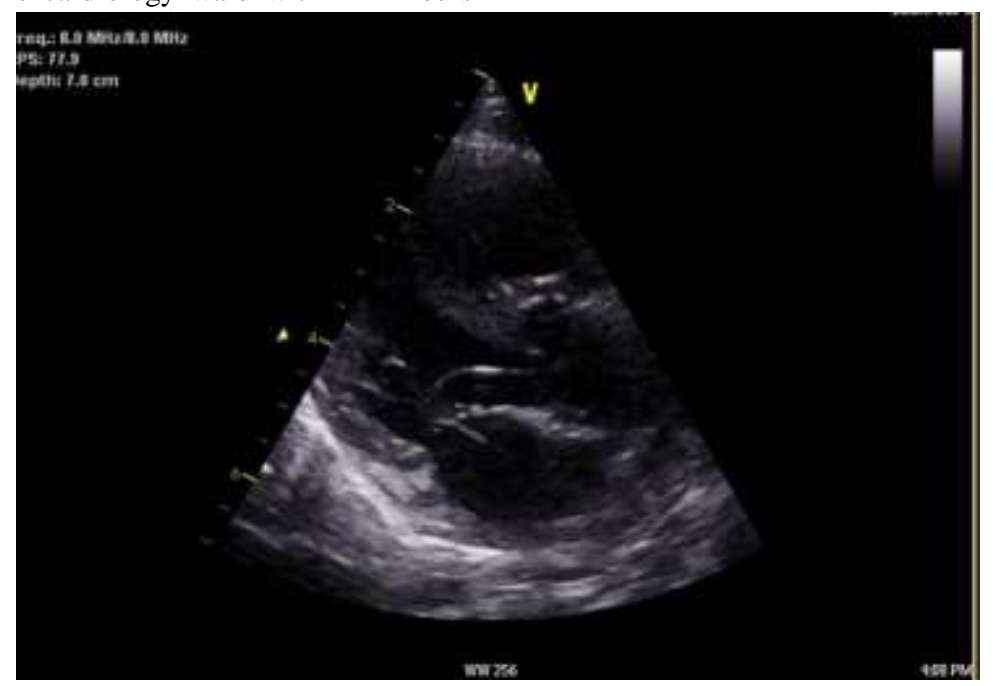

Figure 1a: Transthoracic echocardiogram view in long axis demonstrating the suture traversing the mitral and aortic valve.

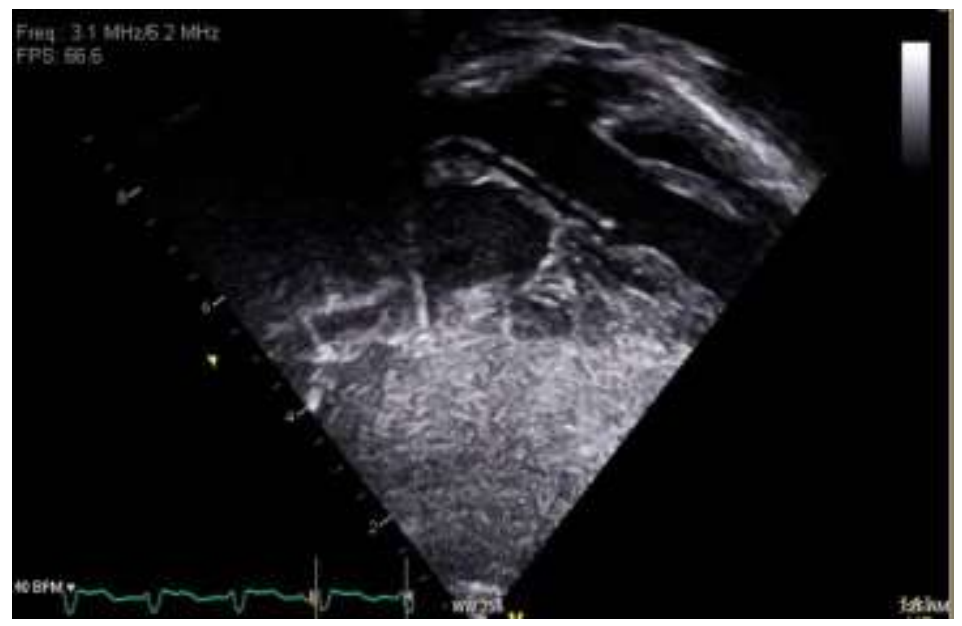

Figure 1b: Subcostal 4 chamber view demonstrating the linear suture originating in the right upper pulmonary vein and passing across the closed mitral valve. 


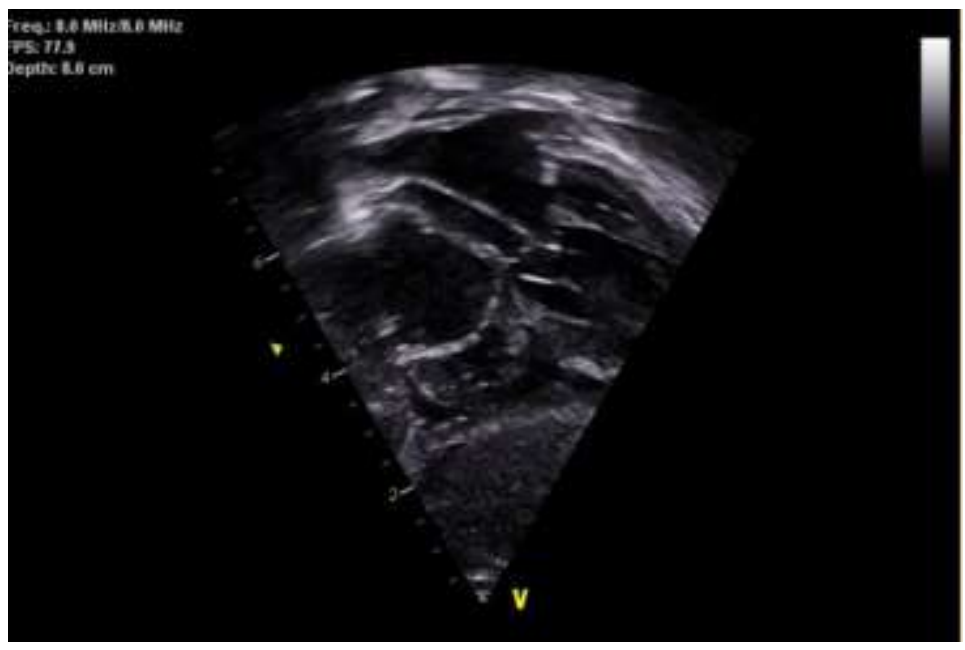

Figure 1c: Subcostal 4 chamber view with a linear suture seen in the left atrium and crossing the open mitral valve.

Due to the unusual appearance of this structure, it was initially thought to be ultrasound artefact. The structure was however repeatedly visualised on repeat echocardiograms. Further imaging was performed to identify the nature of this structure in the form of chest X-ray and fluoroscopy. Neither modality proved to be useful, hence a cardiac CT with contrast was organised. This was reported as demonstrating a thin linear density originating in the right upper lobe pulmonary vein which was likely to be an artefact.

This case was discussed in the joint cardiology and surgical conference and the decision made to perform a surgical re-exploration and removal of the presumed foreign body. Both catheter and surgical options were considered but a surgical approach was chosen due to the uncertainty around the nature of the foreign body, its origin and the potential for intracardiac damage on transcatheter removal.

The previous sternotomy site was re-opened and the patient was placed onto bypass following a final transoesophageal echocardiogram confirming an echogenic strand from the right upper pulmonary vein, through the mitral valve and entering the left ventricular outflow tract with the end seen in the transverse aortic arch, at the level of the innominate artery (Figure 2a-2b).

The aorta was opened transversely and a length of prolene thread was identified in the ascending aorta. The right atrium was opened and the left atrium accessed via widening the existing patent foramen ovale and the thread was identified lying within the left atrium originating from the purse-string suture that had been used for the LV vent. The stitch was removed externally from the right upper pulmonary vein and the sites over sewn. The patient came off bypass uneventfully and the procedure was tolerated well.

The patient was discharged home 4 days following this procedure with no long term sequelae.

\section{Discussion}

Iatrogenic cardiac foreign bodies are rare, particularly suture retention.
Detecting this suture using various imaging modalities was a challenge. Transthoracic echocardiograms repeatedly demonstrated a linear structure originating in the right upper pulmonary vein. This was not reproducible with other imaging modalities including a 128 slice CT scanner due to its radiolucent nature. Our unit practice is to perform a transoesophageal echocardiogram in the operating theatre but in this particular case, this was contraindicated due to the patient's previous transoesophageal fistula repair and therefore an epicardial echocardiogram was performed. We speculate that two aspects of this modality of imaging may have led to the suture not being identified intraoperatively. Firstly the location of the foreign body in the left heart chambers might have lent itself better to detection from transoesophageal imaging. Secondly, the surgical repair of Tetralogy of Fallot is performed exclusively on the right heart structures and therefore intra-operative imaging would have not focused on the left atrioventricular valves.

In this case, repeated transthoracic echocardiography by multiple operators, and a multidisciplinary approach helped make the decision for surgical re-exploration and identify the retained suture.

\section{Conclusion}

We feel it is important for institutional experience in both transoesophageal and transthoracic echocardiography intraoperatively. A high level of suspicion should be held if there are consistent findings by multiple operators' post operatively suggesting a retained foreign body. This is a rare complication and early intervention is important to avoid further harm to the patient.

\section{References}

1. Leitman M, Vered Z. Foreign Bodies in the Heart. Echocardiography. 2015 Feb;32(2):365-371.

2. Actis Dato G, Arslanian A, Marzio P and Ruffini E. Posttraumatic and Iatrogenic Foreign Bodies in the Heart: Report of Fourteen Cases and Review of the Literature. The Journal of Thoracic and Cardiovascular Surgery 2003;126:408-414. 
3. Liu H, Juan Y-H, Saboo S. Foreign Body Venous Transmigration to the Heart. QJM: An International Journal of Medicine. 2014 Sept; 107 (9):743-745.
4. Lewis D, Jivraj A, Jarman R. My Patient is Injured: Identifying foreign bodies with ultrasound. Ultrasound. $2015 \mathrm{Aug}$; 23(3): 174-180.
This work is licensed under Creative Commons Attribution 4.0 License

To Submit Your Article Click Here: Submit Manuscript

DOI:10.31579/2693-2156/014
Ready to submit your research? Choose Auctores and benefit from:

* fast, convenient online submission

* rigorous peer review by experienced research in your field

* rapid publication on acceptance

* authors retain copyrights

* unique DOI for all articles

* immediate, unrestricted online access

At Auctores, research is always in progress.

Learn more https://www.auctoresonline.org/journals/journal-ofthoracicdisease-and-cardiothoracic-surgery- 